\title{
Extracting Storm-Centric Characteristics from Raw Rainfall Data for Storm Analysis and Mining
}

\author{
Kulsawasd \\ Jitkajornwanich \\ Computer Science and \\ Engineering Department \\ Univ. of Texas at Arlington \\ P.O. Box 19015 \\ Arlington, TX 76019 \\ Tel. +1682 4295859 \\ kulsawasdj@hotmail.com
}

\author{
Ramez Elmasri \\ Computer Science and \\ Engineering Department \\ Univ. of Texas at Arlington \\ P.O. Box 19015 \\ Arlington, TX 76019 \\ Tel. +1 8172720067 \\ elmasri@cse.uta.edu
}

\author{
John McEnery \\ Department of Civil \\ Engineering \\ Univ. of Texas at Arlington \\ P.O. Box 19308 \\ Arlington, TX 76019 \\ Tel. +1 8172720234 \\ mcenery@uta.edu
}

\author{
Chengkai Li \\ Computer Science and \\ Engineering Department \\ Univ. of Texas at Arlington \\ P.O. Box 19015
}

Arlington, TX 76019

Tel. +1 8172720162

cli@cse.uta.edu

\begin{abstract}
Most rainfall data is stored in formats that are not easy to analyze and mine. In these formats, the amount of data is enormous. In this paper, we propose techniques to summarize the raw rainfall data into a model that facilitates storm analysis and mining, and reduces the data size. The result is to convert raw rainfall data into meaningful storm-centric data, which is then stored in a relational database for easy analysis and mining. The size of the storm data is less than $1 \%$ of the size of the raw data. We can determine the spatio-temporal characteristics of a storm, such as how big a storm is, how many sites are covered, and what is its overall depth (precipitation) and duration. We present formal definitions for the storm-related concepts that are needed in our data conversion. Then we describe storm identification algorithms based on these concepts. Our storm identification algorithms analyze precipitation values of adjacent sites within the period of time that covers the whole storm and combines them together to identify the overall storm characteristics.
\end{abstract}

\section{Categories and Subject Descriptors}

H.2.8 [Database Management]: Database Applications - spatial databases and GIS, scientific databases; J.2 [Computer Applications]: Physical Sciences and Engineering - earth and atmospheric sciences

\section{General Terms}

Design, Algorithms

\section{Keywords}

Storm analysis, rainfall, precipitation, CUAHSI, ODM

\section{INTRODUCTION}

Most rainfall data is stored in formats that are not easy to analyze and mine. In these formats, the amount of data is enormous. In this paper, we propose techniques to summarize the raw rainfall

Permission to make digital or hard copies of all or part of this work for personal or classroom use is granted without fee provided that copies are not made or distributed for profit or commercial advantage and that copies bear this notice and the full citation on the first page. To copy otherwise, to republish, to post on servers or to redistribute to lists, requires prior specific permission and/or a fee.

ACM SIGSPATIAL BIGSPATIAL'12, November 6, 2012, Redondo Beach, CA, USA.

Copyright $\odot 2012$ ACM ISBN 978-1-4503-1692-7/12/11...\$15.00. data into a model that facilitates storm analysis and mining, and reduces the data size. The result is to convert raw rainfall data into meaningful storm-centric spatio-temporal data, which is then stored in a relational database for easy analysis and mining. The size of the storm data is less than $1 \%$ of the size of the raw data.

Previous storm analysis has mainly been location-specific (either site-specific or region-specific) [1, 2, 3, 4], meaning that each location is considered independently when analyzing a storm. An example would be determining how many storms occurred at site location 376501 in the year 2011. But in reality, a storm covers many locations over a period of time, so location-specific analysis is insufficient. In this work, we propose a climatic application framework that analyzes rainfall data in a storm-specific way. We consider all the locations over time for each storm, so we can determine storm-specific characteristics such as how big the storm is, how many sites are covered, and what is its overall depth and duration. Analyzing the whole storm can give more insight and information since it reflects how a storm actually behaves in nature. In particular, a storm can start at one location and end at another, and the storm typically covers multiple locations at each time point.

It is very difficult to analyze storms directly from the raw data for several reasons. First, the quantity of data is very large that it qualifies as big geospatial data $[19,20]$. Second, the data is stored in a manner that makes it difficult to identify the storms. The data has been gathered as frequently as every five minutes and covers a huge area of observation fields. Traditionally, the data is recorded and stored in either printed or file/folder format. As a result, attempting to do storm analysis with such a large amount of data and the traditional way of storing the data will require manually combining all data across an enormous number of folders and processing them together. This makes it nearly impossible to do storm analysis. It was also documented that converting precipitation data from printed format into digital format (in file/folder), can take up to three years according to a TxDOT project [5].

Our framework allows big precipitation data to be analyzed using relational database by preprocessing, filtering, and discarding unimportant rainfall data and preserving only meaningful storm data that we are interested in. The framework provides a stormspecific approach for analyzing rainfall data by first formalizing storm-related concepts. We then incorporate hydrology concepts and design a customized database schema for storing storm data. This maximizes the ease for hydrologists to perform storm- 
specific analysis and at the same time, follows the global standard of hydrological data model called CUAHSI ODM [10, 12, 23]. Algorithms are developed to identify the different types of storms as described in the formalization and store them using the proposed database schema. Scientists can perform custom storm analysis as needed by using (1) a standard SQL for non-visual (scalar) data analysis such as total rainfall of a storm or (2) our Storm Visualization component for visual (vector) data analysis, which cannot be determined by numerical results in the tables such as storm movement. In addition, data mining techniques such as clustering and classification can be used in storm analysis. Figure 1 is an overview of our framework.

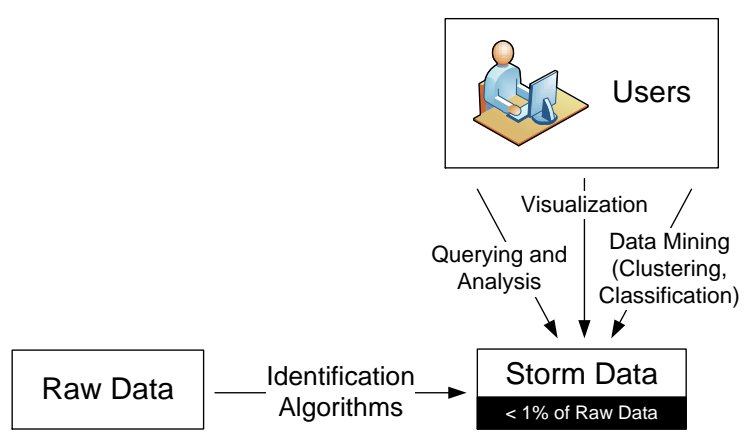

Figure 1. An overview of our framework

The reduction in number of records allows faster querying and mining of the storm data. In our experiments, the number of storm records is less than $1 \%$ of the number of raw data records. In addition, each storm record summarizes the hydrological characteristics of one overall storm. Additional characteristics are available through the related sub storm records.

Since our framework is designed by keeping CUAHSI ODM in mind, it can then be adjusted to apply to other kinds of hydrological observation types as long as they are using the same CUAHSI ODM model, such as soil moisture or river gauge data $[9,10,12,23]$. In addition, our framework is also backwardcompatible with the original location-specific analysis of storms. It can still be used for location-specific storm analysis. That means, our framework can capture the complete spatio-temporal dimensions of storm characteristics: both location-specific and storm-specific. We are hoping that our framework can be a useful tool for hydrologists by helping them to analyze and visualize big precipitation data easier and more efficiently.

The organization of the paper is as follows. In section 2, we describe the raw data used for the system. In section 3 , we formalize the concepts of local, hourly, and overall storms, design a database schema for storing them, and describe the algorithms for identifying these storms from the raw rainfall data. In section 4, we discuss some examples of the analysis that can be performed. Finally, we discuss related work in section 5.

\section{DESCRIPTION OF RAW DATA}

Our raw data comes from National Weather Service - West Gulf River Forecast Center (NWS - WGRFC) (NOAA) and contains 16-year (1996 - 2011) historical hourly precipitation data in Texas and some surrounding areas: Colorado, New Mexico, Louisiana, and part of Mexico, as highlighted in Figure 2 [7, 8]. There is a total of 69,830 site locations observed. The data is received hourly and consists of precipitation data for that particular hour for all
69,830 site locations. This means that the number of records inserted per hour, day, month, and year is $69,830,1,675,920$, $50,277,600$, and $603,331,200$, respectively. Site points are four kilometers apart to north, south, east, and west. The raw data is stored in the database using CUAHSI ODM [10, 23] and has 8.004123763 billion records. However, only 1.25 years of data (October, 2010 - December, 2011) was used in our initial analysis and only Texas was covered. This data has 405,450,691 records of historical hourly precipitation data covering 38,450 sites in Texas. We are now extending the analysis to cover all 16 years of data.

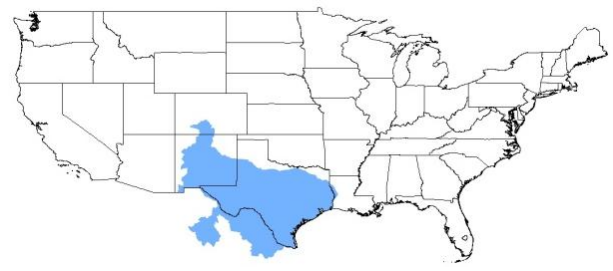

Figure 2. The coverage of WGRFC observations [7, 8]

CUAHSI (Consortium of Universities for the Advancement of Hydrologic Science, Inc.) [12] is a well-known research organization conducting research in the water science-related area since 2001, supported by National Science Foundation (NSF). Hydrologic observation data is gathered from various organizations and kept in various formats. To eliminate the ambiguities in sharing and interpreting hydrological information, CUAHSI ODM [10] was proposed in 2008 [23]. CUAHSI ODM provides a standard schema to store hydrological data in a relational database. In this paper, only the five main tables of CUAHSI ODM will be briefly discussed: Sources, Sites, Methods, Variables and DataValues tables. Figure 3 shows the star-schema [6, Chapter 29] of the five main tables. Appendix A describes these five tables as they were used in our analysis. For more details, please refer to $[10,23]$.

\section{LOCAL, HOURLY, AND OVERALL STORMS: FORMALIZATION, DATABASE SCHEMA, AND IDENTIFICATION ALGORITHMS}

\subsection{Formalization of Storms}

Before defining our storm-related concepts, we specify some predicates (relationships) and terminology that will be used in the definitions.

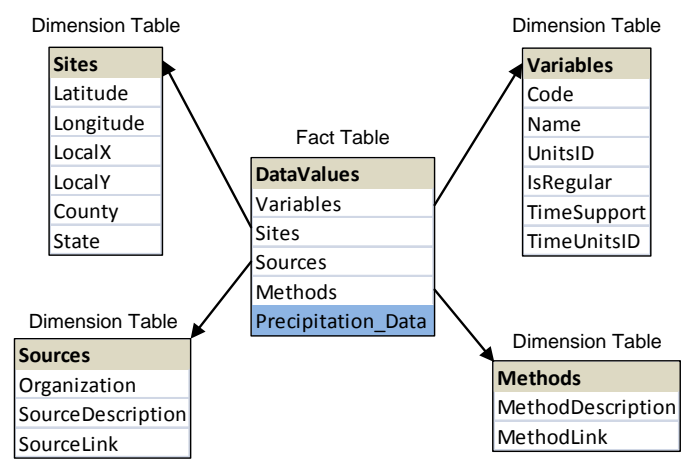

Figure 3. Star-schema of 5 main tables of CUAHSI ODM 
- $\quad$ neighbor $\left(S_{a}, S_{b}, d\right)$ : means that sites $S_{a}$ and $S_{b}$ are adjacent. Referring to Figure 7, if $S_{a}$ is the central site, $S_{b}$ can be any of the other sites. $d$ is the direction from $S_{a}$ to $S_{b}$, and is one of (N, S, E, W, NE, NW, SE, SW).

- $\quad \operatorname{area}(S)$ : the area of site $S$.

- $\quad$ storm duration: the time length over which precipitation occurs (hours) [16].

- storm coverage: the number of sites covered by a storm.

- storm area: the total areas of a storm.

Next, we define the concepts of local storm, hourly storm, and overall storm.

\subsubsection{Local Storm}

Local storm is a set of time points and associated rainfall data at a particular spatial site. Two distinct local storms are separated by at least $h$ consecutive time points with zero precipitation, where $h$ is called the inter-event time $[1,2,17]$. In our case, inter-event time $(h)$ is set to 6 hours. There may be some consecutive time points with zero precipitation within a local storm, as long as it is less than $h$ time points. For any local storm, there will not be a subsequence of $h$ or more consecutive zeroes in the series. A local storm is a site-specific storm, as we see in most hydrology papers $[1,2,3,4]$ that considers each site independently, e.g. determining how many storms occurred at site location 376501 in 2011.

Additional terminology specifically for the local storm definition is as follows:

- storm depth: the amount of precipitation occurring throughout the storm duration at a particular site [16].

- storm intensity: the storm depth divided by the storm duration (inches per hour) [16].

Definition 1. A local storm is represented by $L_{j}\left(s, T_{j}\right)$ where

- $s=$ site id (We assume that the $(x, y)$ HRAP coordinates $[14,10]$ of each site are available from a table and we refer to them as s.x and s.y.)

- $\quad T_{j}$ is the set of (time point, precipitation) that constitutes a local storm $j$ at site $s$, and formalizes the concept that two different local storms at site $s$ must be apart by at least inter-event time. That is:

$T_{j}=\left\{\left(t_{j, i}, p_{j, i}\right) \mid t_{j, i}\right.$ is time $i$ (hourly); $p_{j, i}$ or $p_{\left(t_{j, i}\right.}$ is precipitation from $t_{j, i-1}$ to $t_{j, i}$ (inches), $i=1,2, \ldots, \mathrm{n} ; t_{j, i}$ $t_{j, i-1}=1 ; t_{j, 0}$ is start time and $t_{j, n}$ is end time; $p_{j, k}=p_{j, k+1}=$ $\ldots=p_{j, k+(h-1)}=0$ is false, $k=1,2, \ldots,(\mathrm{n}-h)+1$ and $h=$ inter-event time; $p\left(t_{j, 1}-h\right)=p\left(t_{j, 1}-h+1\right)=p\left(t_{j, 1}-h+2\right)=\ldots$ $=p\left(t_{j, I^{-}}-1\right)=0$ and $p\left(t_{j, n}+1\right)=p\left(t_{j, n}+2\right)=\ldots=p\left(t_{j, n}+h\right)$ $=0 ;$ storm duration $=n ;$ storm depth $=\sum_{i=1}^{n} p_{j, i} ;$ storm intensity $\left.=\frac{\text { storm depth }}{\text { storm duration }}\right\}$

- $\quad L_{j}\left(s, T_{j}\right), j=1,2, \ldots, \mathrm{m}$ are local storms at site $s$ where $L_{l}\left(s, T_{l}\right)$ is the first local storm and $L_{m}\left(s, T_{m}\right)$ is the last local storm. (This formalizes the set of local storms at a particular site.)

\subsubsection{Hourly Storm}

Hourly storm is a set of adjacent sites of local storms at a particular hour. It is built upon and has an orthogonal concept to local storm: instead of considering a site location independently we consider a time point (an hour) independently. Local storm fixes one site and covers its data over many time points, whereas hourly storm fixes a time point and covers its data over many sites.
Additional terminology specifically for the hourly storm definition is as follows:

- storm sites total: the total amount of precipitation occuring at a particular hour for the sites of an hourly storm.

- $\quad$ storm average: the average precipitation (per site) for an hourly storm.

Definition 2. An hourly storm is represented by $H_{j}\left(t, S_{j}\right)$ where

- $\quad t=$ time point (hourly)

- $\quad S_{j}=\left\{\left(s_{j, i}, p_{j, i}\right) \mid s_{j, i}\right.$ is site id $i ; p_{j, i}$ or $p_{(} s_{j, i}$ is precipitation (inches) at site $s_{j, i}, i=1,2, \ldots, \mathrm{n}$; if $|s|=1$, then it contains a single site with no neighbors. Otherwise, every site in the set must have at least one neighbor that is also in the set. That is, if $|s|>1$, then a site $s_{j, i}$ of locations in $S_{j}$ must satisfy: for all $s_{j, i} \in S_{j}$, if neighbor $\left(s_{j, i}, s_{j, k}, d\right)$, then $s_{j, k} \in S_{j}$; storm coverage $=|s|$; storm area $=\sum_{i=1}^{n} \operatorname{area}\left(s_{j, i}\right) ;$ storm sites total $=$ $\sum_{i=1}^{n} p_{j, i} ;$ storm average $\left.=\frac{\text { storm sites total }}{\text { storm coverage }}\right\}$

\subsubsection{Overall Storm}

Overall storm is a storm-specific concept, considering each storm individually as a union of hourly storms. Two neighboring hourly storms must be within a maximum time period $g$, called the grouping-window, and must share at least $n$ common sites, called the spatial-window. Grouping-window is the time interval within which storms will be considered to be part of the same storm. Spatial-window is the number of common site(s) shared between two hourly storms. The concept of overall storm covers both spatial and temporal characteristics of the storm.

Additional terminology specifically for the overall storm definition is as follows:

- $\quad$ storm overall depth: the total amount of precipitation occurring throughout the storm duration across the hourly storms.

- $\quad$ storm overall intensity: the storm overall depth divided by the storm duration (inches per hour).

- storm overall average: the average precipitation (per site) for an overall storm.

Definition 3. An overall storm is represented by $O_{j}$ where

- $\quad O_{j}=\left\{H_{j, i} \mid H_{j, i}\right.$ is an hourly storm, $i=1,2, \ldots, \mathrm{n} ; H_{j, l}$ is the first hourly storm and $H_{j, n}$ is the last hourly storm; $t_{j, k+1}-t_{j, k} \leq$ grouping-window where $t_{j, k}$ is the time of hourly storm $H_{j, k}$ and $\left|S_{j, k+1} \cap S_{j, k}\right| \geq$ spatial-window where $S_{j, k}$ is sites of $H_{j, k}, k=1,2, \ldots, \mathrm{n}-1$; storm duration $=n ;$ storm coverage $=\left|\bigcup_{i=1}^{n} S_{j, i}\right| ;$ storm overall depth $=\sum_{i=1}^{n}$ storm sites total $\left(H_{j, i}\right) ;$ storm overall intensity $=\frac{\text { storm overall depth }}{\text { storm duration }} ;$ storm overall average $=$ $\frac{\text { storm overall depth }}{\text { storm coverage }} ;$ storm area $=\sum_{a \in Z} \operatorname{area}(a), Z=$ $\bigcup_{i=1}^{n} S_{j, i}, S_{j, i}$ is sites of $\left.H_{j, i}\right\}$

The following terms are interchangeable in this paper:

$\begin{array}{ll}\text { - } & \text { Event = Storm } \\ \text { - } & \text { Sub = Hourly } \\ \text { - } & \text { Main = Overall }\end{array}$ 


\subsection{Database Schema for Storms}

Our database schema for storms was designed in such a way that the expressivity and usability features of SQL can be fully utilized in the analysis tasks. SQL and relational databases are proven tools in performing analysis [21, 22]. By designing database schema this way, we can preserve the advantages of SQL and at the same time, the big precipitation data can be analyzed in a relational database.

We store our output, which consists of the identified local, hourly, and overall storms, in relational database tables: LocalEvents, SubStorm, MainStorm, respectively. LocalEvents table stores local storms information for all sites. The information includes date, time, and precipitation depth (in inches) of the storm for a particular site. SubStorm table stores all hourly storms information. The information includes storm sites total, storm average, and storm coverage of an hourly storm. MainStorm table stores information of all overall storms consisting of all sites that were covered during each storm, storm overall depth, storm overall average, and storm overall intensity.

Additional tables were also created: LocationProximity and RA_Sites (Rainfall Analysis Sites table). These will allows us to use SQL during hourly storm and overall storm calculation and utilizes the fact that the raw data that we use resides in a relational database [8, 10, 23]. LocationProximity table stores neighboring site information for each site, which will be used along with LocalEvents table to calculate sub storms. Original CUAHSI ODM does not provide neighboring information in any tables. RA_Sites table stores all site information that we are interested in.

There is a total of five tables created, whose schema diagram is shown in Figure 4 [6, Chapter 3].

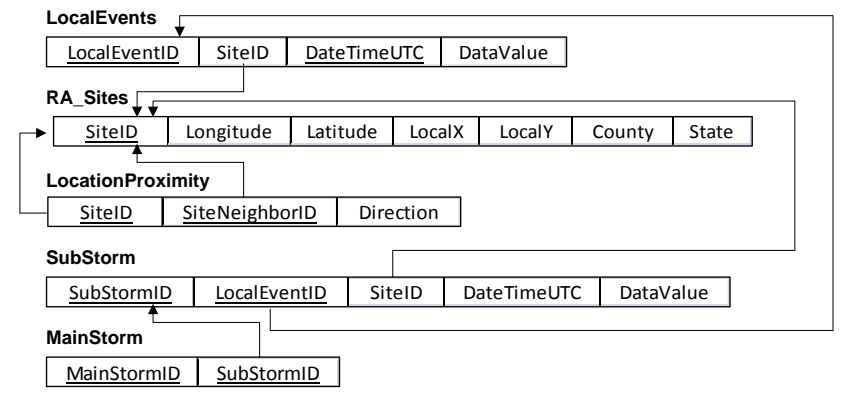

Figure 4. Schema diagram of the output tables

\subsection{Algorithm Development}

The algorithms for storm identification are designed by taking hydrology concepts into account and can be divided into 4 modules:

1. Event Separator

2. Location Proximity Creator

3. Sub Storm Identification

4. Main Storm Identification

The data flow among these modules is shown in Figure 5.

\subsubsection{Event Separator}

This module separates rainfall events (local storms) using 6-hour inter-event time as storm separators. The inter-event time $(h)$ of 6 hours is suggested by Huff $[1,2]$. The input for this module is the

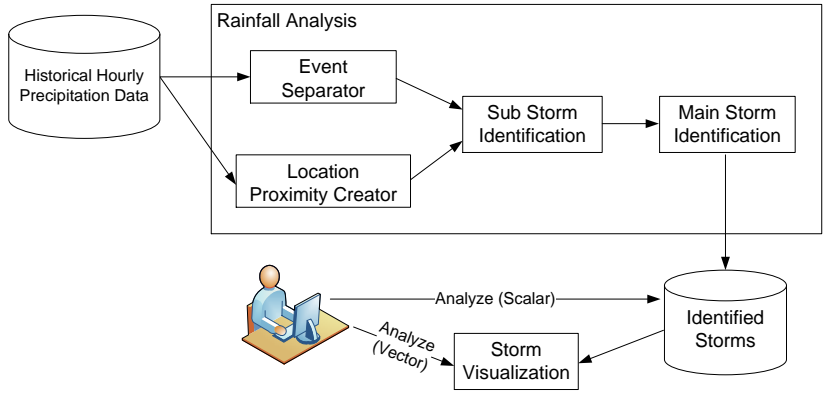

Figure 5. Data flow diagram of storm identification modules

historical hourly precipitation raw data in Texas from the ODM DataValues table (405,450,691 records). The output will be stored in LocalEvents table. An example of LocalEvents table is shown in Table 2. Since the area of Texas is very large, there is a significant climatic difference in its various regions. As a result, USGS (U.S. Geological Survey) divides Texas into 10 regions based on their climatic and geographic characteristics and proposed a map, called Texas Climatic Regions [4], as seen in Figure 6.

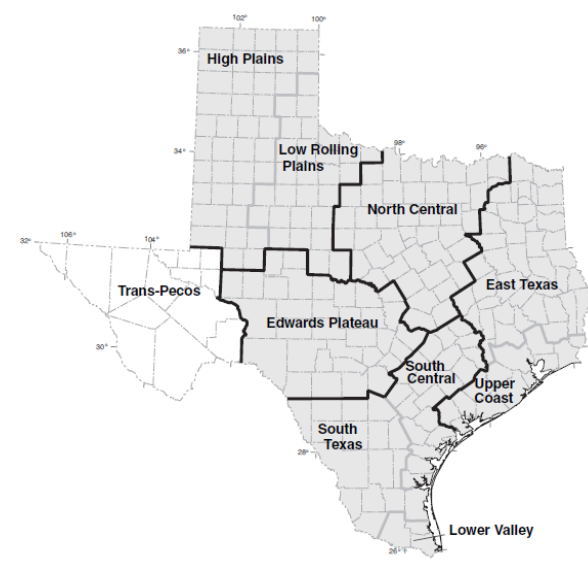

Figure 6. Texas Climatic Regions [4]

To be consistent with USGS, we analyze each region separately. The experimental result (Table 1) indicates that East Texas has the most storm data whereas Trans-Pecos has the least storm data even though Trans-Pecos has more raw data compared to East Texas. This is consistent with the fact that Trans-Pecos is the driest region and East Texas is one of the wettest regions in Texas $[24,25]$.

Table 1. An experimental result of our analysis

\begin{tabular}{|c|c|c|c|c|c|c|}
\hline \multirow[b]{2}{*}{ Regions } & \multirow[b]{2}{*}{$\begin{array}{l}\text { Number of } \\
\text { Raw Data }\end{array}$} & \multicolumn{3}{|c|}{ Number of Identified Storms } & \multirow[b]{2}{*}{$\begin{array}{l}\text { Number of } \\
\text { Storm Data }\end{array}$} & \multirow[b]{2}{*}{$\begin{array}{l}\text { Reduction in } \\
\text { Raw Data Size }\end{array}$} \\
\hline & & $\begin{array}{c}\text { Local } \\
\text { Storms }\end{array}$ & $\begin{array}{l}\text { Hourly } \\
\text { Storms }\end{array}$ & $\begin{array}{l}\text { Overall } \\
\text { Storms }\end{array}$ & & \\
\hline 1. East Texas & $48,953,130$ & 325,504 & 21,983 & 4,632 & 352,119 & $0.72 \%$ \\
\hline 2. Edwards Plateau & $73,415,532$ & 257,859 & 20,136 & 4,191 & 282,186 & $0.38 \%$ \\
\hline 3. High Plains & $31,711,927$ & 97,327 & 8,334 & 2,165 & 107,826 & $0.34 \%$ \\
\hline 4. Low Rolling Plains & $24,965,521$ & 89,814 & 6,199 & 1,487 & 97,500 & $0.39 \%$ \\
\hline 5. North Central & $59,082,957$ & 299,082 & 17,303 & 3,463 & 319,848 & $0.54 \%$ \\
\hline 6. South Central & $31,102,334$ & 120,083 & 11,654 & 3,224 & 134,961 & $0.43 \%$ \\
\hline 7. South Texas & $26,091,999$ & 97,580 & 10,067 & 2,867 & 110,514 & $0.42 \%$ \\
\hline 8. Lower Valley & $11,182,285$ & 41,820 & 4,314 & 1,228 & 47,362 & $0.42 \%$ \\
\hline 9. Trans-Pecos & $65,136,216$ & 151,453 & 11,843 & 3,155 & 166,451 & $0.26 \%$ \\
\hline 10. Upper Coast & $22,863,789$ & 137,843 & 14,043 & 3,255 & 155,141 & $0.68 \%$ \\
\hline
\end{tabular}


We used threads [26] to improve algorithm performance. For each region, sites are equally partitioned into $p$ different disjoint subsets. Each subset is then assigned to one thread. The threads run concurrently and then the results are merged to form LocalEvents table. In our case, $p$ is set to 4 , assuming that each thread occupies each of 4 cores of our computer configuration.

To separate rainfall events for a particular site, a parameter, called inter-event-count, is maintained to keep track of the number of consecutive zero precipitation (sorted by date and time). We use 6 hours inter-event time, as suggested in $[1,2]$. In some situations or applications, a different inter-event time is needed and this can be achieved by changing the parameter in our algorithm to other values such as 24 hours.

Table 2. An example of LocalEvents table

\begin{tabular}{|l|l|l|l|}
\hline LocalEventID & SitelD & DateTimeUTC & DataValue \\
\hline 1 & 654321 & $2012-04-0109: 00$ & 0.2 \\
\hline 1 & 654321 & $2012-04-0110: 00$ & 0.9 \\
\hline 2 & 60000 & $2012-04-0109: 00$ & 0.3 \\
\hline 3 & 45321 & $2012-04-0109: 00$ & 0.1 \\
\hline 3 & 45321 & $2012-04-0110: 00$ & 0.6 \\
\hline 3 & 45321 & $2012-04-0111: 00$ & 0.3 \\
\hline 4 & 50000 & $2012-04-0110: 00$ & 0.8 \\
\hline 4 & 50000 & $2012-04-0111: 00$ & 0.5 \\
\hline
\end{tabular}

\subsubsection{Location Proximity Creator}

This module creates the LocationProximity table containing neighboring sites information for each site. The input of this module is site information from ODM Sites table $[8,10]$. The output will be stored in LocationProximity table. An example is shown in Figure 7.

We calculate neighboring sites information for each site using the HRAP coordinate information [14] labeled as LocalX and LocalY in the ODM Sites table [8, 10, 23]. A site $s(x, y)$ will have the following neighboring sites: $s_{N}(x, y+1), s_{S}(x, y-1), s_{E}(x+1, y)$, $s_{W}(x-1, y), s_{N E}(x+1, y+1), s_{N W}(x-1, y+1), s_{S E}(x+1, y-1)$, and $s_{S W}(x-1, y-1)$ where $(x, y)$ is a HRAP coordinate of site $s$.

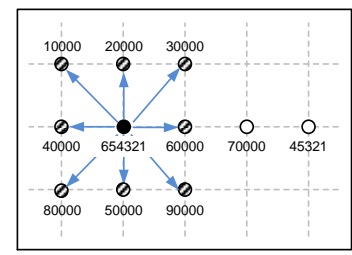

Figure 7. Neighboring sites of site location 654321

\subsubsection{Sub Storm Identification}

This module identifies hourly storms by finding neighboring sites that have precipitation during the same hour. The input of this module is LocalEvents and LocationProximity tables. The output will be stored in the SubStorm table. An example of SubStorm table is shown in Figure 9 and Table 3.

Based on the definition in section 3.1.2, hourly storm is a set of adjacent sites that contain non-zero rainfall in the same time point (hour). The naïve approach is to include all non-zero precipitation values of local storms at a particular hour to be the same hourly storm. However, practically, this could be too rigid. Unanticipated incidents can happen such as equipment malfunctions (not reporting data) or data misreading (reporting incorrect data) since the equipment (physical gauges) can be degraded over time. To keep accuracy of the system intact with small amounts of errors, we introduce a more "relaxed" approach, which incorporates the following two concepts:

\subsubsection{Space-Tolerance}

Informally, space tolerance is to allow non-zero precipitation sites to still be categorized as part of an hourly storm even if they are not in adjacent neighboring sites but are indirect neighboring sites within a certain number of intermediate sites.

Definition 4. We say that site $b$ is an $i$-indirect neighbor of site $a$ if:

$$
\text { neighbor }\left(a, x_{1}\right), \operatorname{neighbor}\left(x_{1}, x_{2}\right), \ldots, \operatorname{neighbor}\left(x_{i}, b\right)
$$

That is, when space-tolerance is set to $n$, the neighbors of site $a$ will include direct neighbors, as well as all $i$-indirect neighbors of $a$ for $i=1,2, \ldots, n$. Figure 8 compares the naïve approach and space-tolerance approach with $n=1$. With the same set of nonzero precipitation values, represented by dots at a particular hour, the naïve approach identifies 2 hourly storms whereas spacetolerance approach identifies 1 hourly storm, which is more practical in reality.

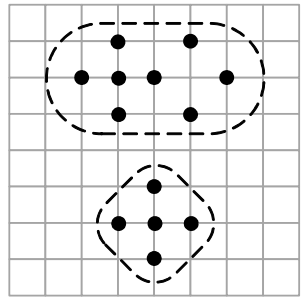

a) Naïve approach

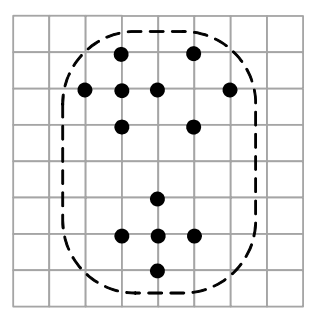

b) Space-tolerance, $n=1$
Figure 8. Comparison between naïve approach and space-tolerance approach

\subsubsection{Outlier Detection}

The space-tolerance mentioned previously only considers if there is a precipitation value at a particular site regardless of whether or not the value is consistent with its neighbors. The space-tolerance concept is good at handling gauge malfunction problems (not reporting data). However, it does not take into account the data values. This outlier detection concept compares the value of precipitation of the current site with its neighbors to detect a potential outlier. This concept will help coping with the data misreading problem. Any outlier detection technique can be implemented. In our example, we only consider eight adjacent neighboring sites when detecting outliers. However, indirect neighboring sites can also be used.

The algorithm is based on recursion and depth-first-search. It checks for each hour to identify how many hourly storms there are, and the sites they cover. To be identified as part of an hourly storm, the sites' location and precipitation value must statisfy the space-tolerance and outlier detection criteria.

\subsubsection{Main Storm Identification}

This module identifies all overall storms (which consist of hourly storms that are sharing some common site(s) (spatial-window $s$ ) within the specified grouping-window $g$ hour(s)) and their storm characteristics. The input of this module is the SubStorm table and 
Table 3. An example of SubStorm table corresponding to Figure 9

\begin{tabular}{|l|l|l|l|l|}
\hline SubStormID & LocalEventID & SiteID & DateTimeUTC & DataValue \\
\hline 1 & 1 & 654321 & $2012-04-0109: 00$ & 0.2 \\
\hline 1 & 2 & 60000 & $2012-04-0109: 00$ & 0.3 \\
\hline 2 & 3 & 45321 & $2012-04-0109: 00$ & 0.1 \\
\hline 3 & 1 & 654321 & $2012-04-0110: 00$ & 0.9 \\
\hline 3 & 4 & 50000 & $2012-04-0110: 00$ & 0.8 \\
\hline 4 & 3 & 45321 & $2012-04-0110: 00$ & 0.6 \\
\hline 5 & 4 & 50000 & $2012-04-0111: 00$ & 0.5 \\
\hline 6 & 3 & 45321 & $2012-04-0111: 00$ & 0.3 \\
\hline
\end{tabular}

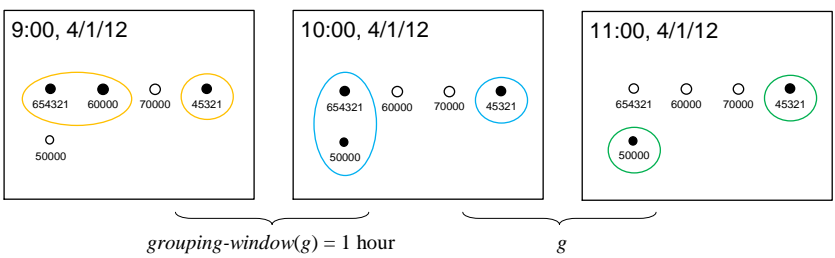

Figure 9. Examples of hourly storms at 9:00, 10:00, and 11:00 on $4 / 1 / 2012$

the output will be stored in the MainStorm table. An example of MainStorm table is shown in Figure 10 and Table 4.

The algorithm has a similar concept as Sub Storm Identification algorithm mentioned previously. However, instead of checking neighboring sites, it checks if sub storms are sharing some common site(s) (spatial-window $s$ ) within the grouping-window $g$ (in hours). In our analysis, grouping-window is 1 hour and spatialwindow is 1 site. That is, if sub storms are within 1 hour difference and sharing at least 1 common site, they will be considered as part of the same overall storm.

Some of our algorithms are outlined in Appendix B.

\section{EXAMPLES OF ANALYSIS PERFORMED ON THE STORM TABLES}

The output of the storm identification algorithms is now stored in three tables: LocalEvents, SubStorm, and MainStorm. We can then perform SQL to do further analysis on these tables such as storm statistical analysis and storm classification. The following is an example of storm statistical analysis, which is to find the statistics of each type of the storms based on storm characteristics (SQL 1 - 3), e.g., storm duration, storm depth, storm intensity, storm sites total, storm average, storm coverage, storm overall depth, storm overall intensity, and storm overall average, whichever is applicable to each type of such storm as described in section 3.1.

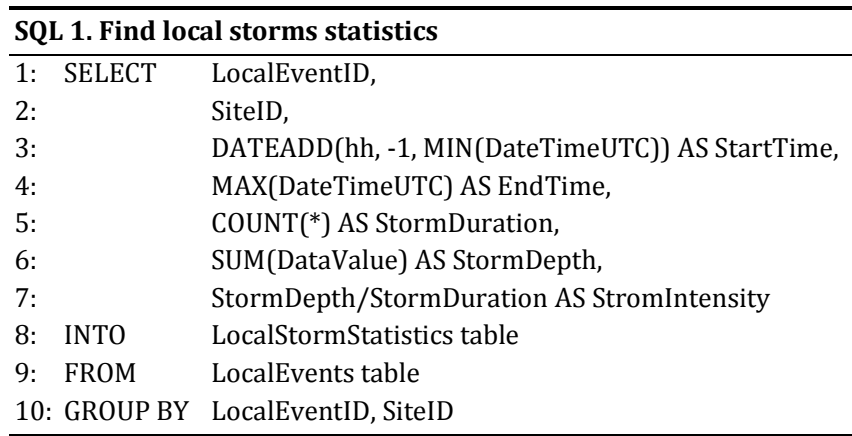

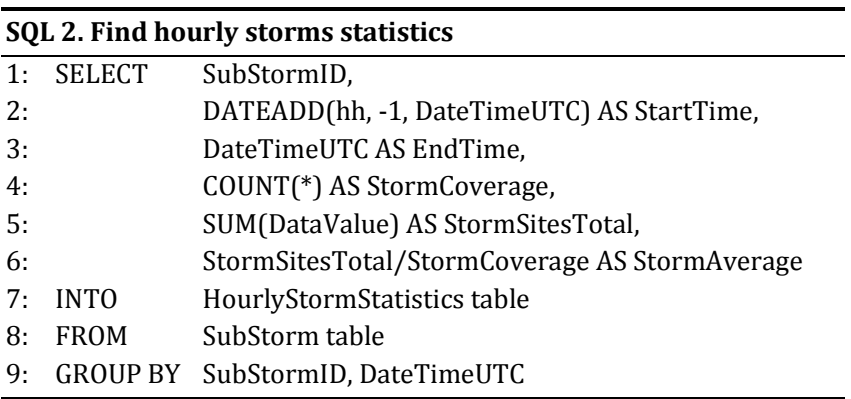

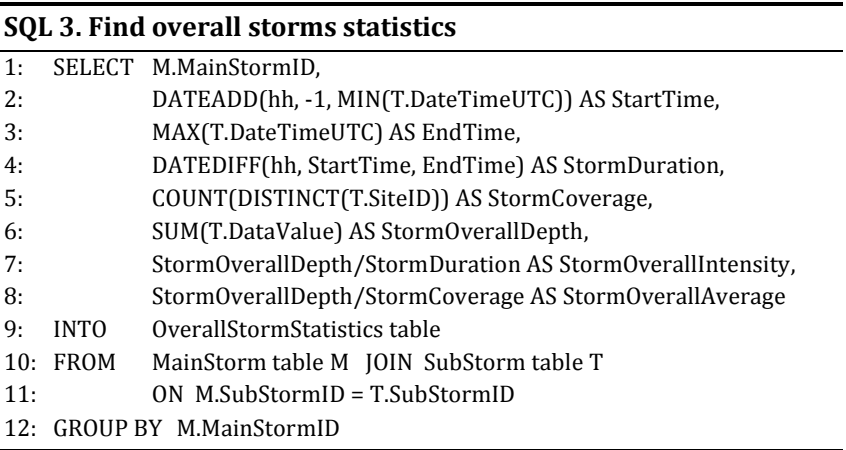

These three queries act as a starting point and can be adapted or customized to many other different kinds of statistical queries such as (1) for local storms, finding the highest local storm in term of storm intensity at site location 376501 during the month of June, 2010; (2) for hourly storms, finding the number of hourly storms with 300 sites or more of storm coverage or 3 inches or more of storm sites total; and (3) for overall storms, finding the five highest overall storms in term of storm overall intensity that are passing site locations 939217 and 686575; by incorporating other types of SQL queries depending on users' application scenarios.

Table 4. An example of MainStorm table corresponding to Figure 10

\begin{tabular}{|l|l|}
\hline MainStormID & SubStormID \\
\hline 1 & 1 \\
\hline 1 & 3 \\
\hline 1 & 5 \\
\hline 2 & 2 \\
\hline 2 & 4 \\
\hline 2 & 6 \\
\hline
\end{tabular}

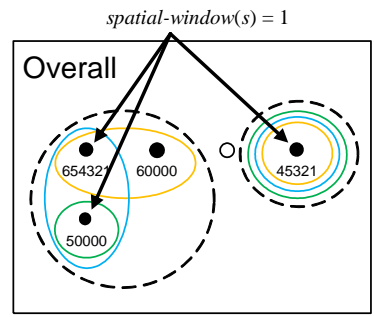

Figure 10. Examples of 2 overall storms on 4/1/2012

Because these three queries are statistical summaries of all three storm types, we pre-compute these three queries and store their results as three additional tables: LocalStormStatistics, 
HourlyStormStatistics, and OverallStormStatistics, with the columns as specified in the query for more convenient analysis. Other storms' characteristics can be also added later as attributes to these tables. Figure 11 shows a small sample analysis performed on the pre-computed OverallStormStatistics table, which is to find the fifty highest overall storms in term of storm duration.

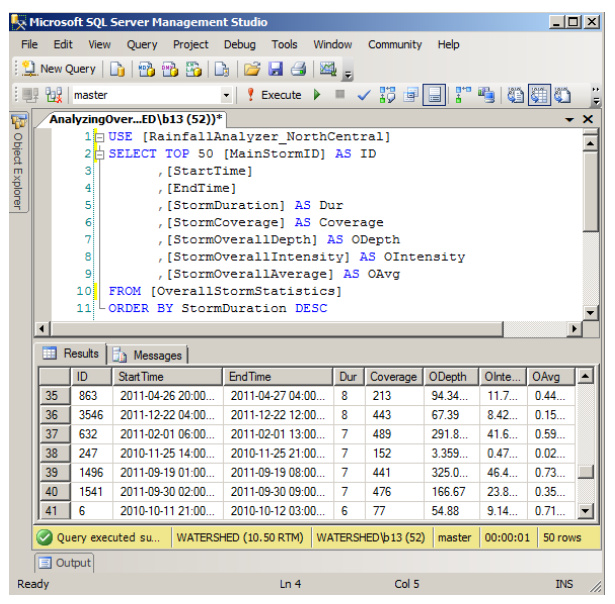

Figure 11. Sample analysis performed on OverallStormStatistics table

For convenience, we also implemented a visualization component, called Storm Visualization, which processes our output storm data to project the resulted overall storms onto a map. Unlike the raster radar images, which are estimated rainfall values that might or might not actually occur, our storm visualization reconstructed the storm from the actual rainfall values. So, it gives more accurate information when doing analysis. The Storm Visualization allows us to capture different aspects of storm characteristics that could not be seen in the table (scalar) results such as storm formation, storm distribution, and storm movement. Figure 13 shows an example of how overall storm ID 863 in North Central region is formed and moves toward the southeast direction. The Storm Visualization component is implemented in C\#, Javascript, HTML5, Google API [13] and ASP.NET.

Figure 12 shows the very first screenshot of the Storm Visualization, which projects the overall storm, 863, onto the map. After triggering by a user, the animation of overall storm (863) is shown as seen in Figure 13. The projection of each hourly storm of the overall storm (863) is shown hour by hour starting at 4/26/2011, 20:00 (Figure 13 (a)). The number in parentheses indicates the number of sub storms involved in that hour.

\section{RELATED WORK}

Several studies suggest that storm characteristics analysis can be done in various ways, such as through its statistical properties, depth-duration frequency (DDF [15]), or focusing on its extreme precipitation values.

Asquith [1] studies storm statistical characteristics including the mean (average) of storm inter-event time, storm depth, and storm duration by analyzing hourly precipitation data retrieved from National Weather Service (NWS) [7]. The data contains 155 million values covering 774 sites in Eastern New Mexico, Texas, and Oklahoma. The storm characteristics results are used to help

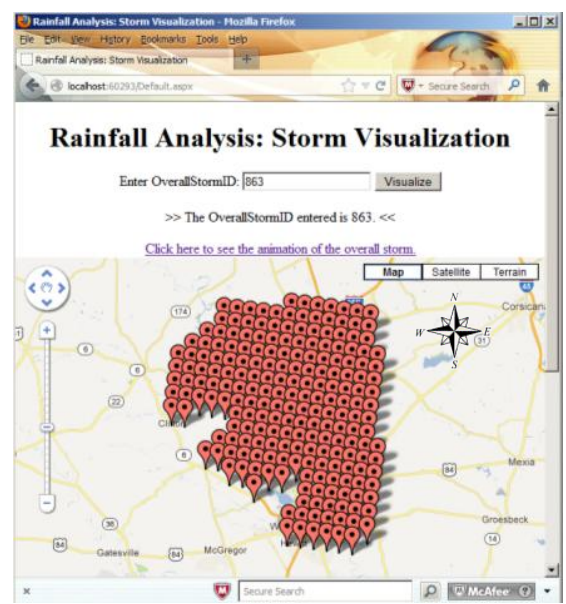

Figure 12. A screenshot of overall storm ID 863

in designing and creating a new runoff control structure. The outputs are in two formats: maps and tables.

[1]'s raw data is stored in file and folder format which raises the difficulty in combining all data across an enormous number of folders and processing them together. Consequently, a huge manual effort is needed to do the analysis. In addition, its analysis has been location-specific (site-specific and regional-specific). So, the storm-specific information is lacking from the work.

For our work, on the other hand, the raw data is stored in the standard CUAHSI ODM database schema, which reflects to the future trend of using hydrological data in this standard format. Our framework can do the analysis in an automated way and process a much larger number of sites. Our algorithm is also customizable through parameters such as inter-event time so it does not need to be fixed to any set of inter-event times, in particular as seen in [1]'s work. Not only can our approach support location-specific analysis but it supports storm-specific analysis as well. So, the complete dimensions of storm characteristics can be analyzed. The following is a small example of how our approach can also be used in location-specific analysis. Suppose we want to find the mean storm depth for Tarrant County, Texas (region-specific storm analysis), we can then perform the following query (SQL 4) on one of our output tables, which store storm information (LocalStormStatistics), to get the answer.

\begin{tabular}{ll}
\hline SQL & 4. Find mean storm depth for Tarrant County, Texas \\
\hline 1: & SELECT AVG(StormDepth) \\
2: & FROM LocalStormStatistics table \\
3: & WHERE SiteID IN (SELECT SiteID \\
4: & FROM RA_Sites table \\
5: & WHERE State = 'Texas' AND County = 'Tarrant' ) \\
\hline
\end{tabular}

In [2, 3], Asquith and Roussel study storm characteristics through its Depth-Duration Frequency (DDF [15]) property. [2] presents a procedure to develop a DDF at any location in Texas for the following 14 storm durations: 15, 30, and 60 minutes; 1, 2, 3, 6, 12 , and 24 hours; and 1, 2, 3, 5, and 7 days with recurrence intervals ranging from 2 to 500 years. DDF is an estimated depth of the storm given its duration and frequency (recurrence time). It is very important when creating an efficient control structure such 


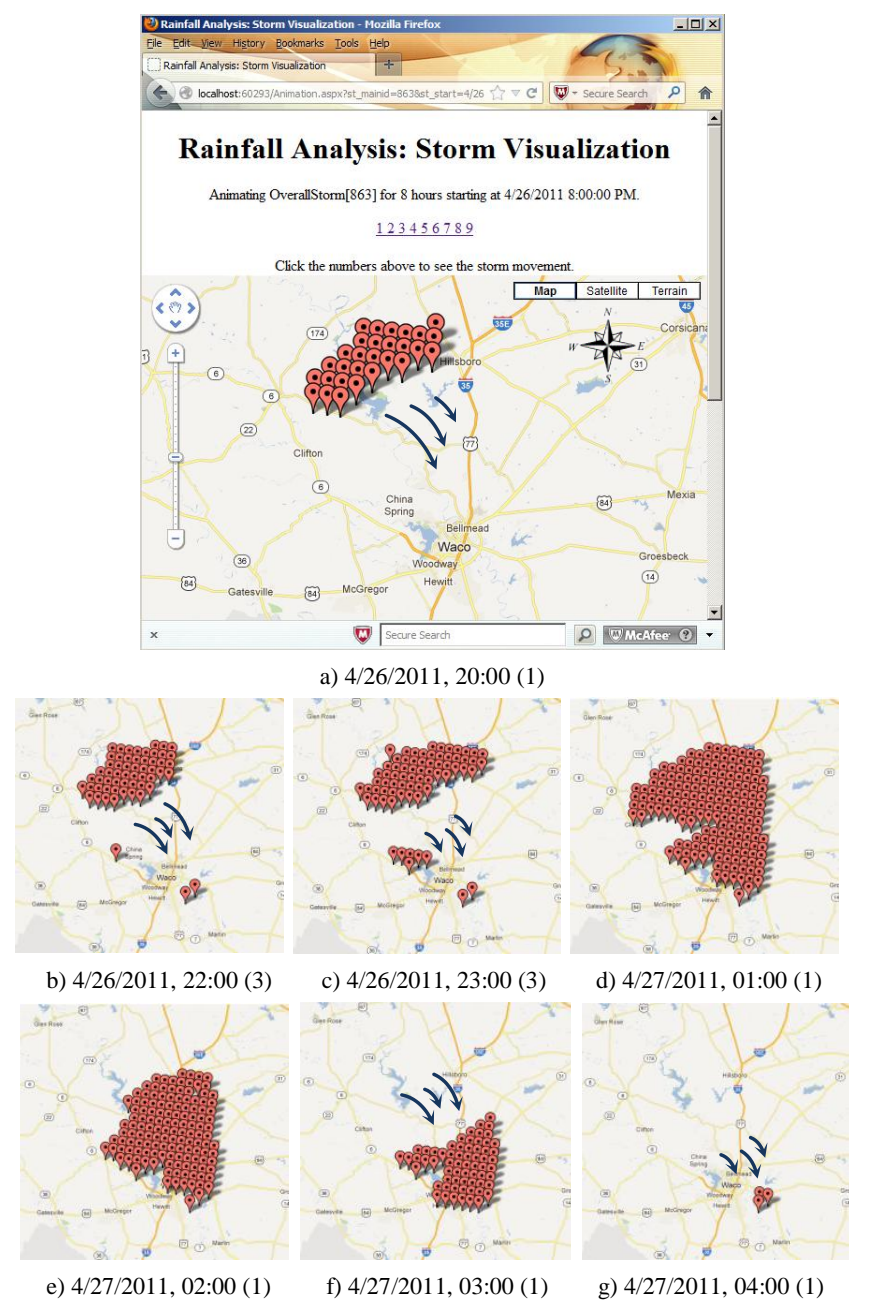

Figure 13. An animation of overall storm (ID: 863) by its sub storms and the arrows show the direction of the storm

as storm drains or parking lots. It is also used to design efficient river flow and flood prediction models. As a result, it has to be very accurate. To calculate DDF for a storm duration and frequency at any location, we need three storm depths (in inches) retrieved from three maps (location, scale, shape parameter maps) for that storm duration and a storm intensity (in inches per hour) retrieved from precipitation intensity-duration curve of that storm frequency. Then, plug all values into the equation given in the paper [2] and the result is an estimated storm depth for that particular storm.

[3] is an extension of [2]. However, it does not require users to do the calculation themselves. It provides pre-computed DDF maps, which are ready to use. The set of storm durations and storm frequencies, however, are different from [2]. The storm durations only include 15, and 30 minutes; 1, 2, 3, 6, and 12 hours; and 1, 2, 3,5 , and 7 days and the storm frequencies only include $2,5,10$, 25, 50, 100, 250, and 500 years.

One of the key tasks of $[2,3]$ is to create location, scale, and shape parameter maps used in the approach. To create such maps, this work uses storm data from National Climatic Data Center (NCDC) [11]. However, only location-specific storm data (by county) is provided by NCDC. So, generating these required maps will be limited to location-specific storm data. In addition, even though NCDC stores storm data in a database, CUASHI ODM was not mentioned as its database schema. As a result, incorporating our storm data (storm-specific) into these two works may enhance their analytic capabilities.

Lanning-Rush [4] studies storm characteristics by focusing on its extreme precipitation (EP) values. The extreme precipitation depth refers to one that exceeds 100 -year or greater storm depth. Unlike [1] that considers all storms, only extreme storms were taken into account in this work. Unlike $[2,3]$ that the inputs are storm duration, frequency and location, it only takes storm duration and area as inputs. The goal of this work is to create the extreme precipitation curve which can be used to estimate extreme precipitation depth for a particular storm duration and area. The EP curves are developed from 24 extreme storms out of 213 notable storms. They select storm durations to include 1, 2, 3, 4, 5, and 6 days and the areas include High Plains, Low Rolling Plains, North Central, Edwards Plateau, South Central, South Texas, East Texas, Upper Coast, and Lower Valley in Texas. Trans-Pecos area, however, was excluded due to the lack of its storm data.

\section{CONCLUSION AND FUTURE WORK 6.1 Conclusion}

In this paper, we presented a framework for converting the large amounts of rainfall data into storm-specific summaries. The resulting storm data is $1 \%$ of the original raw data, and can be easily analyzed and mined using SQL queries and other methods. We first formalized various types of storms that can be identified from standard raw rainfall data. We then developed a customized database schema and algorithms to automate the storm identification process, and to store the identified storms and their characteristics in relational database tables. Analysis tasks can be done in two ways: via SQL for scalar analysis or via our initial Storm Visualization for vector analysis.

\subsection{Future Work}

For future work, we will develop data mining techniques such as classification, clustering, time series mining, and association rules mining in order to find other interesting characteristics of storms as well as work on calculating other significant measurements such as storm area, storm center, and within storm variations [18].

\section{REFERENCES}

[1] Asquith, W. H. et al. 2006. Statistical Characteristics of Storm Interevent Time, Depth, and Duration for Eastern New Mexico, Oklahoma, and Texas. Professional Paper 1725. U.S. Geological Survey (USGS).

[2] Asquith, W. H. 1998. Depth-Duration Frequency of Precipitation for Texas. Water-Resources Investigations Report 98-4044. U.S. Geological Survey (USGS).

[3] Asquith, W. H. \& Roussel, M. C. 2004. Atlas of DepthDuration Frequency of Precipitation Annual Maxima for Texas. Scientific Investigations Report 2004-5041 (TxDOT Implementation Report 5-1301-01-1). U.S. Geological Survey (USGS).

[4] Lanning-Rush, J. et al. 1998. Extreme Precipitation Depth for Texas, Excluding the Trans-Pecos Region. Water-Resources Investigations Report 98-4099. U.S. Geological Survey (USGS).

[5] Asquith, W. H. et al. 2004. Synthesis of Rainfall and Runoff Data used for Texas Department of Transportation Research 
Projects 0-4193 and 0-4194. Open-File Report 2004-1035. U.S. Geological Survey (USGS).

[6] Elmasri, R. \& Navathe, S. 2010. Fundamentals of Database Systems ( $6^{\text {th }}$ edition). Pearson Education, Massachusetts.

[7] National Oceanic and Atmospheric Administration (NOAA). 2011. National Weather Service River Forecast Center: West Gulf RFC (NWS-WGRFC). Retrieved December 31, 2011, from: http://www.srh.noaa.gov/wgrfc/.

[8] McEnery, J. 2011. CUAHSI HIS: NWS-WGRFC Hourly Multi-sensor Precipitation Estimates. Retrieved December 31, 2011, from: http://hiscentral.cuahsi.org/pub_network.aspx? $n=187$.

[9] Consortium of Universities for the Advancement of Hydrologic Science, Inc. (CUAHSI). 2008. HydroDesktop. Retrieved October 26, 2011, from: http://his.cuahsi.org/hydrodesktop.html.

[10] Consortium of Universities for the Advancement of Hydrologic Science, Inc. (CUAHSI). 2008. ODM Databases. Retrieved October 26, 2011, from: http://his.cuahsi.org/odmdatabases.html.

[11] NOAA Satellite and Information Service. 2012. National Climatic Data Center (NCDC). Retrieved March 15, 2012, from: http://www.ncdc.noaa.gov/oa/ncdc.html.

[12] Consortium of Universities for the Advancement of Hydrologic Science, Inc. (CUAHSI). 2008. Universities Allied for Water Research. Retrieved October 26, 2011, from: http://www.cuahsi.org/.

[13] Google. 2012. Google Developers: Google Maps API. Retrieved April 14, 2012, from: https://developers.google.com/maps/.

[14] NOAA's National Weather Service. 2011. The XMRG File Format and Sample Codes to Read XMRG Files. Retrieved December 31, 2011, from: http://www.nws.noaa.gov/oh/hrl/dmip/2/xmrgformat.html.

[15] Overeem, A. et al. 2008. Rainfall Depth-Duration-Frequency Curves and Their Uncertainties. Journal of Hydrology 348 (1-2), 124-134.

[16] Virginia Department of Conservation and Recreation. 2012. Stormwater Management: Hydrologic Methods. Retrieved May 2, 2012, from: http://dcr.cache.vi.virginia.gov/stormwater_management/documents/Chapter_4.pdf.

[17] Asquith, W. H. 2005. Summary of Dimensionless Texas Hyetographs and Distribution of Storm Depth Developed for Texas Department of Transportation Research Project 04194. Report 0-4194-4. U.S. Geological Survey (USGS).

[18] Suyanto, A. et al. 1995. The Influence of Storm Characteristics and Catchment Conditions on Extreme Flood Response: A Case Study Based on the Brue River Basin, U.K. Surveys in Geophysics 16(2), 201-225.

[19] Franks, B. 2012. Taming The Big Data Tidal Wave: Finding Opportunities in Huge Data Streams with Advanced Analytics. John Wiley \& Sons, Inc., Hoboken, New Jersey.

[20] DevZone. 2011. Big Data Bibliography. O’Reilly Media.

[21] Linoff, G. 2007. Data Analysis Using SQL and Excel. Wiley Publishing, Inc., Indianapolis, Indiana.

[22] Cameron, S. 2009. Microsoft ${ }^{\circledR}$ SQL Server ${ }^{\circledR} 2008$ Analysis Services Step by Step. Microsoft Press, Redmond, Washington.

[23] Horsburgh, J. S. et al. 2008. A Relational Model for Environmental and Water Resources Data, Water Resources Research.

[24] George, W. B. 2012. WEATHER: The Handbook of Texas Online. Retrieved September 5, 2012, from: http://www.tsha- online.org/handbook/online/articles/yzw01. Texas State Historical Association.

[25] Frontier Associates, LLC. 2008. Texas Renewable Energy Resource Assessment. Texas State Energy Conservation Office.

[26] Freeman, A. 2010. Pro .NET 4 Parallel Programming in C\#. Springer-Verlag, New York.

\section{APPENDIX A}

This appendix section briefly summarizes the five main tables of CUAHSI ODM tables: Sources, Methods, Sites, Variables, and DataValues tables.

The Sources table stores information about where the observation data comes from. Table 5 shows our Sources table in the database.

Table 5. Sources table in the database

\begin{tabular}{|c|l|l|l|}
\hline ID & \multicolumn{1}{|c|}{ Organization } & \multicolumn{1}{c|}{ SourceDescription } & \multicolumn{1}{c|}{ SourceLink } \\
\hline 1 & $\begin{array}{l}\text { NOAA's National Weather Service } \\
\text { West Gulf River Forecast Center }\end{array}$ & $\begin{array}{l}\text { Files containing MPE data } \\
\text { from NWS-WGRFC }\end{array}$ & $\begin{array}{l}\text { http://www.srh.no } \\
\text { aa.gov/wgrfc/ }\end{array}$ \\
\hline
\end{tabular}

The Methods table describes how the observation is collected. A brief explanation of the method along with its external link is also provided in this table. Table 6 shows our Methods table in the database.

Table 6. Methods table in the database

\begin{tabular}{|c|l|l|}
\hline ID & \multicolumn{1}{|c|}{ MethodDescription } & \multicolumn{1}{c|}{ MethodLink } \\
\hline 1 & $\begin{array}{l}\text { The precipitation data are multi-sensor } \\
\text { (radar, satellite, and rain gauge). }\end{array}$ & $\begin{array}{l}\text { http://www.srh.noaa.gov/rfcshare/precip_ } \\
\text { about_hourly.php }\end{array}$ \\
\hline
\end{tabular}

The Sites table stores site information. The site information includes SiteID, Longitude, Latitude, LocalX, LocalY, County, State, etc. We have a total of 38,450 sites. Table 7 shows selected columns of our Sites table in the database.

Table 7. Selected columns of Sites table

\begin{tabular}{|c|c|c|c|c|c|c|}
\hline ID & Latitude & Longitude & LocalX & LocalY & County & State \\
\hline 339072 & 31.0444 & -97.9782 & 573 & 200 & Tarrant & Texas \\
\hline 339073 & 31.0402 & -97.9379 & 574 & 200 & Tarrant & Texas \\
\hline 339074 & 31.0359 & -97.8976 & 575 & 200 & Tarrant & Texas \\
\hline
\end{tabular}

The next table is Variables table. The information about observation is stored in this table. Each variable represents different observation types and properties. The property information includes how frequent the observation is recorded (instantaneous or consistent) and what unit is used for the observation values.

That is, for example, hourly precipitation observation and 15minute interval precipitation observation are considered different variables due to their properties even though they both are the same precipitation observation types.

We have one variable as demonstrated in Table 8, which is hourly precipitation data. 
Table 8. Selected columns of Variables table

\begin{tabular}{|c|c|c|c|c|c|c|}
\hline ID & Code & Name & UnitsID & IsRegular & TimeSupport & TimeUnitsID \\
\hline 1 & MPE & Precipitation & 49 & 1 & 1 & 103 \\
\hline
\end{tabular}

The last main table is DataValues table. This table stores numerical observation values for each site and variable as well as the method used and the source where they are from. Table 9 shows some samples of what DataValues table entries look like. The first row of the table states that we have no rain (precipitation value $=0$ ) at site location 88814 from noon to $1 \mathrm{pm}$ on October 1 , 2011. As we can see that regardless of whether or not we have rain, the precipitation value is inserted into the table. As a result, the database grows rapidly and sparse.

Table 9. Some examples of DataValues table entries with selected columns

\begin{tabular}{|c|c|c|c|c|c|c|}
\hline ID & DataValue & DateTimeUTC & SitelD & VariableID & MethodID & SourcelD \\
\hline 1 & 0 & $2011-10-0113: 00$ & 88814 & 1 & 1 & 1 \\
\hline 2 & 0 & $2011-10-0113: 00$ & 88815 & 1 & 1 & 1 \\
\hline 3 & 0 & $2011-10-0113: 00$ & 88816 & 1 & 1 & 1 \\
\hline
\end{tabular}

\section{APPENDIX B}

This appendix section briefly describes some of our algorithms.

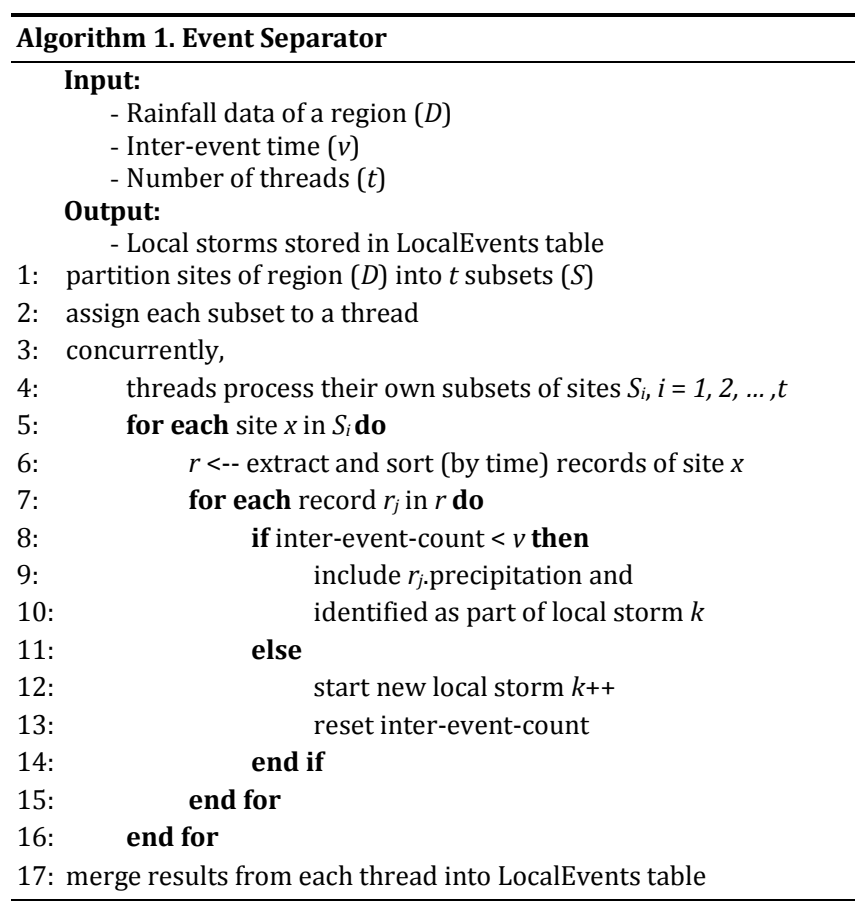

- Rainfall data of a region $(D)$

- Inter-event time $(v)$

currently,

threads process their own subsets of sites $S_{i}, i=1,2, \ldots, t$

$r<--$ extract and sort (by time) records of site $x$

each record $r_{j}$ in $r$ do

start new local storm $k++$

reset inter-event-coun

end for

esults from each thread into LocalEvents table

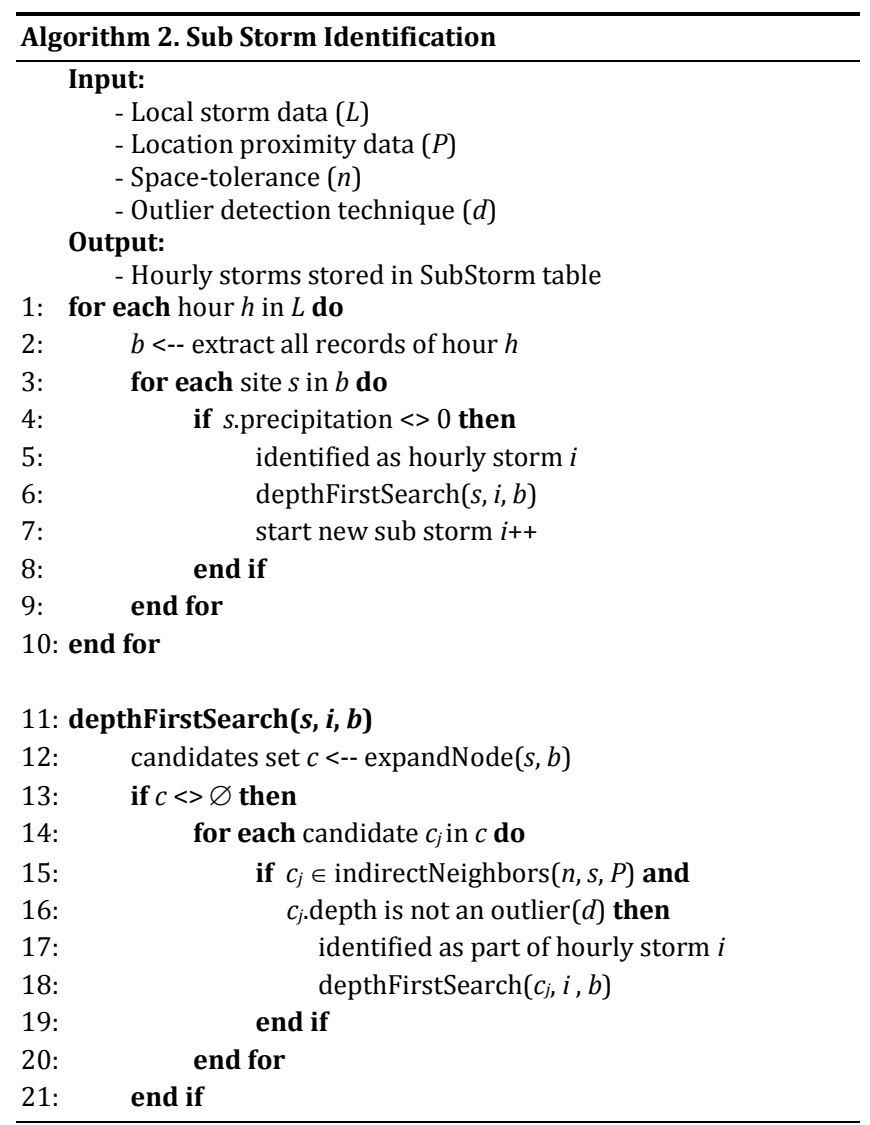

